\title{
Optimization of Process Parameters of Nickel - Chromium Electroplating for Thickness Variation using Genetic Algorithm
}

\author{
D. Khedekar' ${ }^{1}$, V. Gosavi' ${ }^{2}$ C. Gogte ${ }^{3}$ and P. Brahmankar ${ }^{4}$ \\ ${ }^{1}$ Associate professor, MGM's JNEC, Aurangabad, India \\ ${ }^{2}$ Assistant Professor, CHH Collage of Engineering, Aurangabad, India \\ ${ }^{3}$ Professor, MIT, Aurangabad, India \\ ${ }^{4}$ Professor, BATU, Lonere, India \\ \{dskhedekar@gmail.com
}

\begin{abstract}
Surface is very critical from quality point of view which affecting the life and the performance of products. Surface properties can be improved by number of methods, but electroplating is preferred because of its enhanced results at lower cost. In this work nickel chrome is selected for experimentation as it is widely used in industry especially in automotive sectors for plating many of the automotive components. The electroplating of nickel chrome not only improves the surface properties but also aesthetics of the component which is also a vital part of automobile requirement. Experiments are planned by Taguchi L16 orthogonal array and effect of density of solutions and time for processes at two levels on thickness variation is studied. Mathematical model were developed by regression analysis for thickness variation. Genetic Algorithm is used for optimization of process parameters. It was observed that the effect of time is more dominating for the thickness variation.
\end{abstract}

\section{Keywords: Surface Engineering, Anodic, Semi Bright, Genetic Algorithm}

\section{Introduction}

Surface of any mechanical element is important as performance and working life of the element depends on it. The economics of the processing is the main concern of the industry. Surface preparation processes contribute to the cost and durability of the product so it's critical and electroplating contributes a lot in surface properties enhancement than other methods. Depending upon specific requirement, different plating materials are selected such as zinc, nickel, chromium, nickel chrome etc. Nickel chrome is widely used in many applications especially in automotive industries. Nickel chrome plating improves the corrosion resistance, hardness, wear resistance, improve aesthetic look and improve surface properties independent of substrate. Almost $12 \%$ of worlds nickel chromium produced is just used for electroplating, justifying its importance in surface improvement so there is continuous need to still improve the process. Many researchers have studied electroplating with different aspect. Nickel zinc electroplating process optimization is done to set factor to optimum value for hydrogen evolution affecting plating [1]. Optimization of nickel, copper and hard chromium coating by multiple electroplating process is done for thickness of plating [2]. Improvement in thickness of deposition for amount and distribution of nickel been plated is done by proper racking and placement of the part in solution and by using theirs shields and auxiliary anode [3]. Effect of time, temperature, current and density on nickel in electroplating characteristics in supercritical CO2 is studied [4]. Improving the throwing power of nickel electroplating baths for improving deposition is studied [6]. Non uniformity leads to thickness variation affecting the functional requirement so more thought is to be given to the thickness variation in electroplating process [7]. In the present work study of thickness variation is done. Experimentation is done by L16 orthogonal array and effect of time and density is studied for thickness variation. Mathematical model are developed using regression for different factor setting at different levels. Genetic Algorithm is used to optimize the process parameters.

B. Iyer, S. Nalbalwar and R. Pawade (Eds.)

ICCASP/ICMMD-2016. Advances in Intelligent Systems Research.

Vol. 137, Pp. 41-47.

(C) 2017. The authors - Published by Atlantis Press

This is an open access article under the CC BY-NC license (http://creativecommons.org/licens)es/by-nc/4.0/).

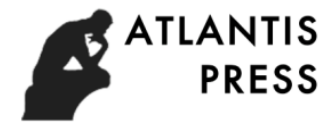




\section{Experimental Work}

Electroplating is the electrolytic deposition of a metal from a solution onto the surface of substrate immersed in

solution. Part to be plated is submerged in the bath and electric current is applied. The part is in the centre of plating tank as cathode and the anodes of plating material are positioned near the edges of tank, deposition takes place based on Michael Faradays Laws. The set-up used is of Zumtara Electroplating industry. The steps of process are cleaning, rinsing and electroplating. The set- up has a series of tanks with different solution as per the process. The setup of electroplating is as shown in figure 1.

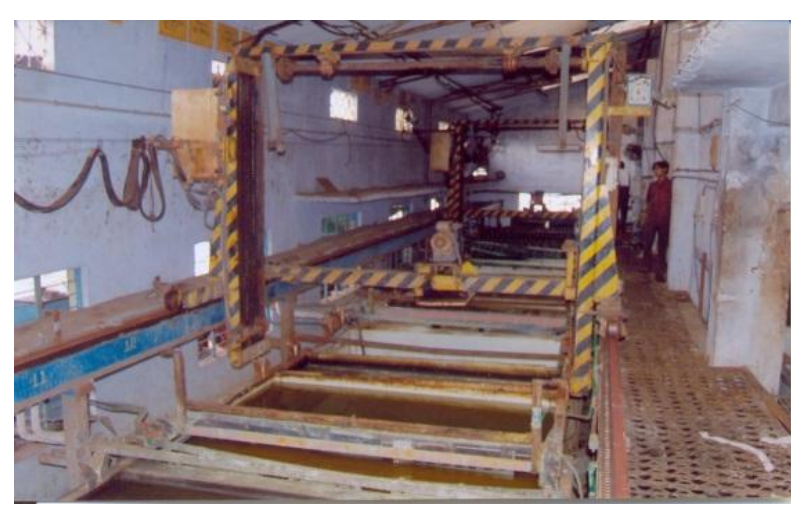

Fig. 1. Setup of Electroplating

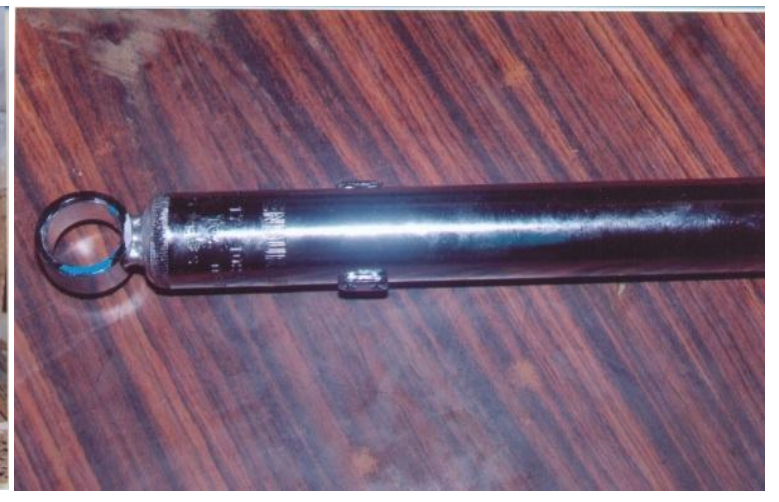

Fig. 2. Outer Tube of Shock Absorber

\subsection{Material}

For the study the experimentation work was performed on the outer tube of shock absorber that is $250 \mathrm{~mm}$ in length and $45 \mathrm{~mm}$ diameter. The product is as shown in figure 2. The material steel cold drawn containing carbon-0.20 max., Mn- 0.30-0.60, S-0.60 max and P-0.060 max. The plating material deposited on the product is nickel and chromium.

\subsection{Technique}

Experimentation is carried by Taguchi's L16 orthogonal array. Following the array randomly experimentation was carried out. On the plating jigs number of components to be plated are adjusted and are dip in solutions to carry processes on number of components simultaneously. Three components electroplated are selected randomly for set parameter process and thickness of plating is checked at three different locations per component. The complete process of cleaning, rinsing and plating is a continuous sequential process carried in 8 steps as shown in table 1 with two levels of factor time and density.

\section{Table 1 Factor Setting Values for Two Levels}

\begin{tabular}{|c|c|c|c|c|c|c|c|c|c|c|c|c|c|c|c|c|}
\hline Factors & \multicolumn{16}{|c|}{ Processes } \\
\hline \multirow[b]{2}{*}{ Levels } & \multicolumn{2}{|c|}{ Degreasing } & \multicolumn{2}{|c|}{ Anodic } & \multicolumn{2}{|c|}{ HCL } & \multicolumn{2}{|c|}{$\mathrm{H}_{2} \mathrm{SO}_{4}$} & \multicolumn{2}{|c|}{ Semibright } & \multicolumn{2}{|c|}{ Triplex } & \multicolumn{2}{|c|}{ Bright } & \multicolumn{2}{|c|}{ Chrome } \\
\hline & I & II & I & II & I & II & I & II & $\mathrm{I}$ & II & I & II & I & II & I & II \\
\hline Time(min) & 5 & 8 & 3 & 5 & 2 & 5 & 2 & 3 & 20 & 24 & 3 & 5 & 14 & 16 & 3 & 5 \\
\hline Density(g/L) & 10 & 13 & 6 & 10 & 5 & 10 & 10 & 20 & 19 & 22 & 19 & 24 & 19 & 24 & 19 & 24 \\
\hline
\end{tabular}

\subsection{Thickness testing}

Thickness of plating is measured by Smart GEDET tester. This device work on principle opposite to electroplating it remove the coating of material working on coulometric principle. The thickness of plating layers of bottom semi bright is 12 to $14 \mu \mathrm{m}$, middle triplex is 2 to $3 \mu \mathrm{m}$ and top bright layer is 9 to $10 \mu \mathrm{m}$. i.e. total nickel chrome electroplating thickness is 24 to $25 \mu \mathrm{m}$. 


\section{Results and Discussion}

In order to have more accurate results randomly the experiments were carried out for three times and three different components were checked at three locations in a sample for thickness. Form the reading noted of a component, maximum and minimum value gives thickness variation. Average of three different component thickness variations is taken. The results were analysed to investigate the effects of time and density parameters at two levels for each step of degreasing, anodic, HCL, H2SO4, semi bright, triplex bright and chrome for thickness variation of electroplating.

\subsection{Regression analysis}

The lower thickness variation is considered as better result. The result of thickness variation due to time and density variation is as shown in table 2 and table 3 respectively.

Table 2 Thickness variation with time of processes

\begin{tabular}{|l|l|l|l|l|l|l|l|l|l|}
\hline \multirow{2}{*}{$\begin{array}{c}\text { Trail } \\
\text { No. }\end{array}$} & \multicolumn{7}{|c|}{ Factor Time (Min.) } & \multicolumn{2}{c|}{ Thickness } \\
\cline { 2 - 9 } & T1 & T2 & $\begin{array}{l}\text { T } \\
3\end{array}$ & T4 & T5 & T6 & T7 & $\begin{array}{c}\text { T } \\
8\end{array}$ & \\
\hline 01 & 5 & 3 & 2 & 2 & 20 & 3 & 14 & 3 & 6.765 \\
\hline 02 & 5 & 3 & 2 & 2 & 20 & 3 & 14 & 5 & 4.895 \\
\hline 03 & 5 & 3 & 2 & 3 & 24 & 5 & 16 & 3 & 6.53 \\
\hline 04 & 5 & 3 & 2 & 3 & 24 & 5 & 16 & 5 & 6.66 \\
\hline 05 & 5 & 5 & 5 & 2 & 20 & 5 & 16 & 3 & 4.03 \\
\hline 06 & 5 & 5 & 5 & 2 & 20 & 5 & 16 & 5 & 5.16 \\
\hline 07 & 5 & 5 & 5 & 3 & 24 & 3 & 14 & 3 & 5.3 \\
\hline 08 & 5 & 5 & 5 & 3 & 24 & 3 & 14 & 5 & 5.43 \\
\hline 09 & 8 & 3 & 5 & 2 & 24 & 3 & 16 & 3 & 6.53 \\
\hline 10 & 8 & 3 & 5 & 2 & 24 & 3 & 16 & 5 & 6.86 \\
\hline 11 & 8 & 3 & 5 & 3 & 20 & 5 & 14 & 3 & 6.38 \\
\hline 12 & 8 & 3 & 5 & 3 & 20 & 5 & 14 & 5 & 6.2 \\
\hline 13 & 8 & 5 & 2 & 2 & 24 & 5 & 14 & 3 & 7.1 \\
\hline 14 & 8 & 5 & 2 & 2 & 24 & 5 & 14 & 5 & 6.1 \\
\hline 15 & 8 & 5 & 2 & 3 & 20 & 3 & 16 & 3 & 5.35 \\
\hline 16 & 8 & 5 & 2 & 3 & 20 & 3 & 16 & 5 & 5.65 \\
\hline
\end{tabular}


Thickness Variation versus T1, T2, T3, T4, T5, T6, T7 and T8 i.e. for time of process.

The regression equation for thickness variation $=3.63+0.225 \mathrm{~T} 1-0.419 \mathrm{~T} 2-0.132 \mathrm{~T} 3+0.007 \mathrm{~T} 4+0.190 \mathrm{~T} 5$ $+0.086 \mathrm{~T} 6-0.087 \mathrm{~T} 7-0.064 \mathrm{~T} 8$

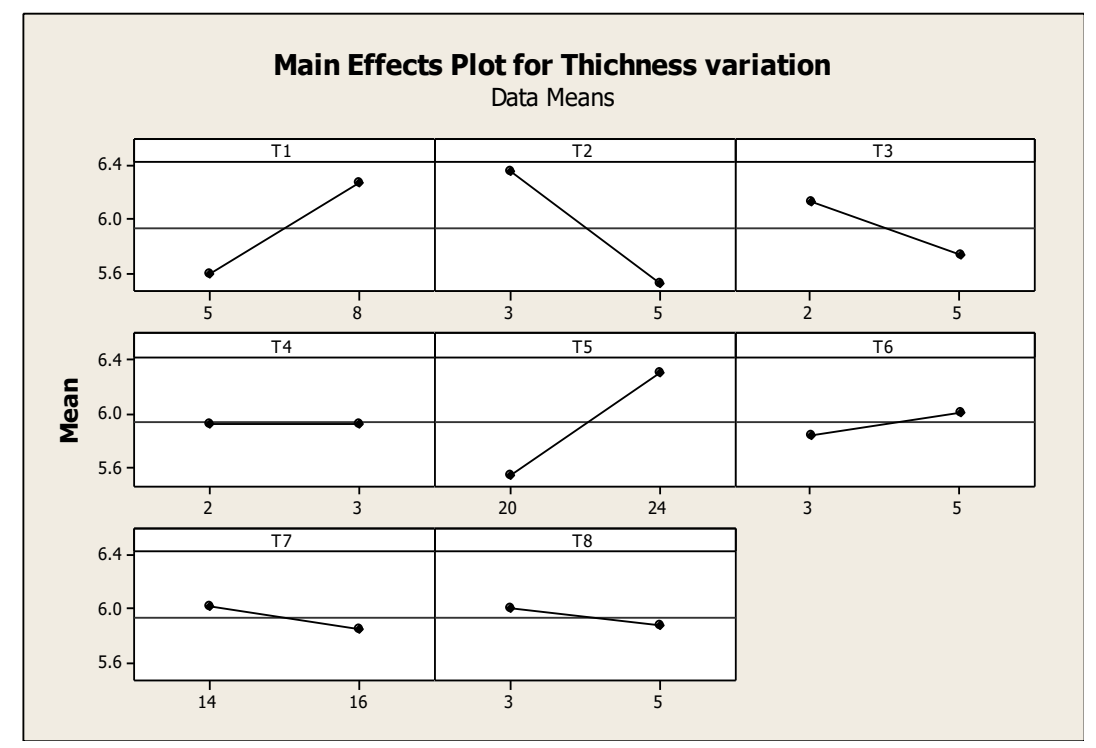

Fig. 3. Main effect plot for thickness variation with time

From the main effect plots as shown in figure 3 it was found that the thickness variation is more affected by cleaning process such as degreasing and anodic with more time of anodic cleaning thickness variation reduces, also semi bright plating is affecting the thickness variation with time as the major thickness of plating is of semi bright i.e. 12 to $14 \mu \mathrm{m}$.

Table 3Thickness variation with density solution

\begin{tabular}{|l|l|l|l|l|l|l|l|l|c|}
\hline \multirow{2}{*}{$\begin{array}{l}\text { Trail } \\
\text { No. }\end{array}$} & \multicolumn{7}{|c|}{ Factor Density(g/L) } & \multicolumn{1}{c|}{$\begin{array}{c}\text { Thickness } \\
\text { Variation }(\mu \mathrm{m})\end{array}$} \\
\cline { 2 - 9 } 01 & 10 & 6 & 10 & 10 & 19 & 24 & 24 & 19 & 6.766 \\
\hline 02 & 10 & 6 & 5 & 10 & 19 & 19 & 19 & 24 & 5.447 \\
\hline 03 & 10 & 6 & 5 & 20 & 22 & 24 & 24 & 19 & 6.749 \\
\hline 04 & 10 & 6 & 5 & 20 & 22 & 24 & 24 & 24 & 6.690 \\
\hline 05 & 10 & 10 & 10 & 10 & 19 & 24 & 24 & 19 & 4.998 \\
\hline 06 & 10 & 10 & 10 & 10 & 19 & 24 & 24 & 24 & 4.940 \\
\hline 07 & 10 & 10 & 10 & 20 & 22 & 19 & 19 & 19 & 5.269 \\
\hline 08 & 10 & 10 & 10 & 20 & 22 & 19 & 19 & 24 & 5.109 \\
\hline 09 & 13 & 6 & 10 & 10 & 22 & 19 & 24 & 19 & 6.490 \\
\hline 10 & 13 & 6 & 10 & 10 & 22 & 19 & 24 & 24 & 6.790 \\
\hline 11 & 13 & 6 & 10 & 20 & 19 & 24 & 19 & 19 & 6.444 \\
\hline 12 & 13 & 6 & 10 & 20 & 19 & 24 & 19 & 24 & 6.385 \\
\hline 13 & 13 & 10 & 5 & 10 & 22 & 24 & 19 & 19 & 6.504 \\
\hline 14 & 13 & 10 & 5 & 10 & 22 & 24 & 19 & 24 & 6.445 \\
\hline 15 & 13 & 10 & 5 & 20 & 19 & 19 & 24 & 19 & 5.404 \\
\hline 16 & 13 & 10 & 5 & 20 & 19 & 19 & 24 & 24 & 5.459 \\
\hline & & & & & & & & \\
\hline
\end{tabular}


Thickness Variation versus D1, D2, D3, D4, D5, D6, D7, D8 i.e. density of solutions.

The regression equation for thickness variation $=-0.11+0.183 \mathrm{D} 1-0.225 \mathrm{D} 2-0.0344 \mathrm{D} 3-0.0054 \mathrm{D} 4+0.194$ D5 + 0.102 D6 + 0.0203 D7 - 0.0229 D8

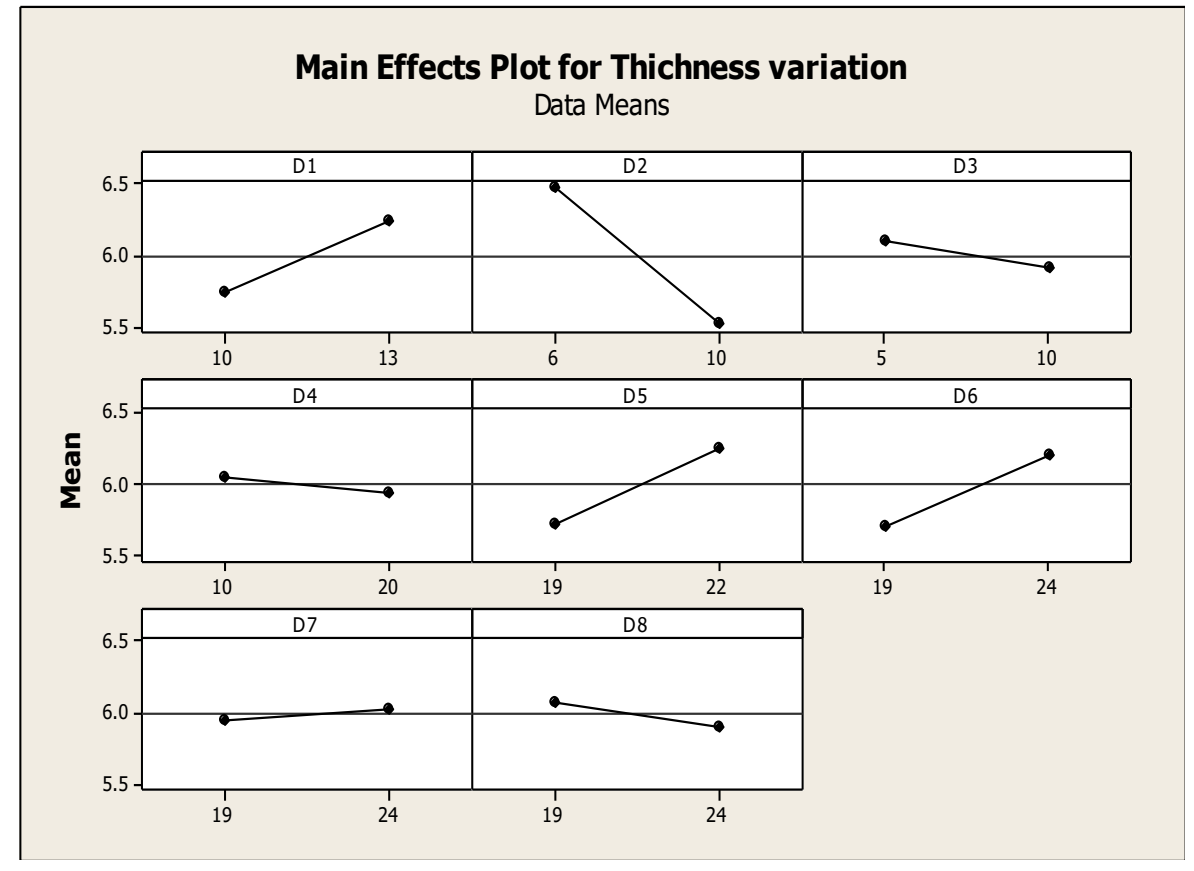

Fig. 4. Main effect plot for thickness variation with density solution

From the main effect plot for effect of density, as shown in figure 4 it is found just like time, with density of solutions cleaning process affect the thickness variation most also in actual plating semi bright and triplex affect the most. Semi bright is base plating layer and triplex is intermediate layer which binds the upper layer with the semi bright layer. At lower density of plating solutions we get minimum thickness variation.

\subsection{Optimization}

The mathematical model developed with regression analysis is into a MATLAB (R2009a) function and then optimized by GA.

In the objective function $\mathrm{f}(1)$ is for thickness variation with time,

function $\mathrm{f}=\operatorname{singleobjTT}(\mathrm{y})$

$\mathrm{f}(1)=1 /(1+3.63+(0.225 * \mathrm{y}(1))-(0.419 * \mathrm{y}(2))(0.132 * \mathrm{y}(3))+(0.007 * \mathrm{y}(4))+(0.190 * \mathrm{y}(5))+(0.086 * \mathrm{y}(6))-(0.087 * \mathrm{y}(7))-$ $(0.064 * \mathrm{y}(8))) ;(3)$

In the objective function $\mathrm{f}(1)$ is for thickness variation with density,

function $\mathrm{f}=\operatorname{singleobjDT}(\mathrm{y})$

$\mathrm{f}(1)=1 /(1-0.11+(0.183 * \mathrm{y}(1))-(0.225 * \mathrm{y}(2))-(0.0344 * \mathrm{y}(3))-$

$(0.0054 * \mathrm{y}(4))+(0.194 * \mathrm{y}(5))+(0.102 * \mathrm{y}(6))+(0.0203 * \mathrm{y}(7))-(0.0229 * \mathrm{y}(8)))$;

Table 4 Details of GA for time and density variation on thickness variation

\begin{tabular}{|l|l|}
\hline GA for time variation & GA for density variation \\
\hline Solver: ga- Genetic Algorithm & Solver: ga- Genetic Algorithm \\
Fitness function: @ singleobjT & Fitness function: @ singleobjD \\
Number of variables : 08 & Number of variables : 08 \\
Lower Bounds: $[5,3,2,2,20,3,14,3]$ & Lower Bounds: [10,6,5,10,19,19,19,19] \\
Upper Bounds: $[8,5,5,3,24,5,16,5]$ & Upper Bounds: [13,10,10,20,22,24,24,24] \\
Iteration required: 55 & Iteration required: 51 \\
\hline
\end{tabular}


These function was used as input to the GA Toolbox of MATLAB 2009a as the objective function. The upper and lower bounds were specified as per the levels of the parameters and the number of variables was set at 8 . The objective function values are obtained for minimum thickness variation. Initial population size of 60 is taken and simple crossover and bitwise mutation with a crossover probability $\mathrm{Pc}=0.8$, migration interval of 20 , migration fraction of 0.2 and Pareto fraction of 0.35 was set for optimization. The details of GA for time and density variation is as shown in table no. 3

According to the algorithm, ranking and sorting of solutions are done and reported in table 5 From the result shown in table optimum value of thickness variation with effect of time is $7.471 \mu \mathrm{m}$ and for density variation is $7.416 \mu \mathrm{m}$. so the effect of time is more dominating for the thickness variation.

Table 5 Details of optimize values

\begin{tabular}{|l|l|l|l|l|l|l|l|l|l|l|}
\hline $\begin{array}{c}\text { Sr. } \\
\text { No. }\end{array}$ & $\begin{array}{c}\text { Fact } \\
\text { ors }\end{array}$ & Iteration & Degreasing & Anodic & HCL & $\mathbf{H}_{\mathbf{2}} \mathbf{S O}_{\mathbf{4}}$ & Semibright & Triplex & Bright & Chrome \\
\hline 1 & $\begin{array}{l}\text { Tim } \\
\mathrm{e}\end{array}$ & 55 & 7.994 & 3.019 & 2.048 & 2.689 & 23.997 & 4.997 & 14.168 & 3.082 \\
\hline 2 & $\begin{array}{l}\text { Dens } \\
\text { ity }\end{array}$ & 51 & 12.997 & 6.088 & 5.109 & 12.239 & 21.99 & 23.994 & 23.787 & 19.064 \\
\hline
\end{tabular}

\section{Conclusions}

Investigation in nickel-chrome electroplating process is done to study effect of parameters during plating processes on thickness variation. Based on observation following conclusions are drawn:

1. Optimum thickness variation is affected more by time than density of solution

2. Considering time factor, the cleaning process as degreasing and anodic affect more and among the plating semi bright process contributes more to the thickness variation. Thickness variation is less with lower time and it increases with semi bright process time.

3. Considering density factor effect on thickness variation, both cleaning as degreasing and anodic affect thickness variation, anodic affect the most also the semi bright and triplex plating affects with lower density of solutions to lower thickness variation.

4. Most influencing processes during the electroplating that are affecting thickness variation are degreasing, anodic, semi bright, and triplex.

\section{Acknowledgement}

I am very much thankful to Zumtara Press Chrome Pvt. Ltd.

\section{References}

[1]. Chi-Change $\mathrm{Hu}$ and Allen Bai, "Optimization of the hydrogen evolution activity on zinc-nickel deposits using experimental strategies”, Journal of Electrochimica Acta, vol-48, 2003, pp.-907-918

[2]. Wang Deging, Shi Ziyuan, Kou Tangshan, "Composite plating of hard chromium on aluminum substrate", Journal of surface and coating Technology, vol. 20, 2004, pp 1-6.

[3]. George A. Dibari, "Nickel Plating”, 'published by International Nickel Inc, Saddle Brook, N.J. pp 270288.

[4]. Moon-sun kim, Jae-Youn kim, "Study on the effect of temperature and pressure on nickelelectroplating Characteristics in supercritical CO2", Published in Journal of Chemoshphere, Vol 30, 2004, pp-1-7.

[5]. D. S. Khedekar, Dr. S. K. Biradar, V. Y. Gosavi, “Optimization of Nickel - Chromium Electroplating Process for Corrosion Resistance Using Genetic Algorithm," International Journal of Modern Trends in Engineering and Research,(2016).

[6]. Z. Abdel Hamid, "Improving the throwing power of Nickel electroplating bath", Journal of Materials chemistry and physics, vol. 53, 1998, pp 253-238.

[7]. Yong-Jun Tan, Kim Yong Lim, "Understanding and Improving the Uniformity of Electrodosition", Journal of Surface and coating Technology, vol-167, 2003. 
[8]. Y.M. Kuo and C.S. Wang, "Characteristics of chromium droplets generated form gas bubbling in chromium electroplating processes”. Journal of Aerosol sci. Vol 29, 1998, pp 1223-1224.

[9]. P.G.Karad, D.S.Khedekar."Optimization of Turning Process during Machining of Al-SiC Using Genetic Algorithm.'Published in International Journal of Modern Trends in Engineering and Research,2016.

[10]. Mohler, J.B. Sedusky, “Electroplating”, published by New York: McGraw Hill Book, 1978

[11]. Blum, William/ Hogaboom, "Principles of electroplating and electroforming", Published by new York: McGraw - Hill book, 1949.

[12]. Philip J. Ross, “Taguchi Techniques for quality Engineering”, Published by MeGraw-Hill book company, "Handbook on Electroplating" Published by W. Canning and Co. Ltd.

[13]. K.S. Rajagopalan, "Introduction to electroplating and metal finishing”, Bombay: colour Pub. 